\title{
Adrenal Gland Sarcoma
}

National Cancer Institute

\section{Source}

National Cancer Institute. Adrenal Gland Sarcoma. NCI Thesaurus. Code C156956.

A rare sarcoma that arises from the adrenal gland. 